\title{
Erratum to: Impact of the Syrian Crisis on the Hospitalization of Syrians in a Psychiatric Setting
}

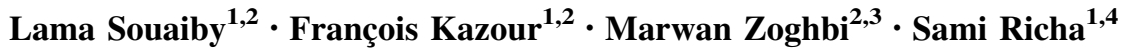

Published online: 12 February 2016

(C) Springer Science+Business Media New York 2016

\section{Erratum to: Community Ment Health J (2016) 52:84-93 \\ DOI 10.1007/s10597-015-9891-3}

In the online published article by Souaiby et al., entitled Impact of the Syrian Crisis on the Hospitalization of
Syrians in a Psychiatric Setting (Community Ment Health J. 2015 May 16. Epub ahead of print), the authors' names were incorrectly listed.

The corrected authors' name list is as follows: "Lama Souaiby, François Kazour, Marwan Zoghbi, and Sami Richa."

The online version of the original article can be found under doi:10.1007/s10597-015-9891-3.

Sami Richa

samiric@idm.net.lb

1 Department of Psychiatry, Saint-Joseph University, Beirut, Lebanon

2 Psychiatric Hospital of the Cross, Jal Eddib, Jdeideh, Lebanon

3 Department of Family Medicine, Saint-Joseph University, Beirut, Lebanon

4 Hotel-Dieu de France, Beirut, Lebanon 